\title{
Anselm Lenhard
}

\section{Die Vorschläge zur Reform des englischen Mobiliarkreditsicherungsrechts}

\author{
Ein Wegweiser für eine europäische Harmonisierung?
}

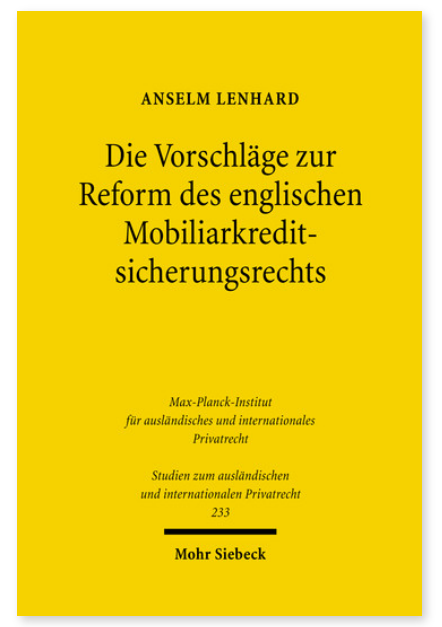

2010. XXVIII, 391 Seiten. StudIPR 233

ISBN 978-3-16-151418-0

DOI 10.1628/978-3-16-151418-0

eBook PDF 89,00€

ISBN 978-3-16-150057-2

fadengeheftete Broschur 89,00€
Die Unterschiede der nationalen Mobiliarkreditsicherungsordnungen im Zusammenspiel mit der lex rei sitae -Regel des IPR bergen für Kreditgeber das Risiko des Verlusts ihrer Sicherheit in grenzüberschreitenden Fällen. Diese mit dem Gedanken eines Europäischen Binnenmarkts kaum zu vereinbarende Problematik nimmt Anselm Lenhard zum Ausgangspunkt seiner Untersuchung zu den Reformbemühungen auf dem Gebiet des Mobiliarkreditsicherungsrechts in England. Nach einer umfassenden Darstellung des gegenwärtigen Rechtszustands diskutiert er die bislang erfolglosen Reformversuche, die sich am US-amerikanischen Vorbild (Art. 9 UCC) orientieren. Der Autor ordnet die englischen Reformvorschläge in die internationale Diskussion über die sachgerechte Regelung dieses Rechtsgebiets ein (insbesondere UNCITRAL Legislative Guide on Secured Transactions) und skizziert Wesenszüge eines zukünftigen europäischen Harmonisierungsprojekts.

Anselm Lenhard Geboren 1979; Studium der Rechtswissenschaft in Konstanz und Würzburg; 2005 Europajurist (Univ. Würzburg); 2006 Forschungsaufenthalt in London; 2009 Promotion; seit 2007 Referendar im Bezirk des OLG Frankfurt.

\section{Jetzt bestellen:}

https://mohrsiebeck.com/buch/die-vorschlaege-zur-reform-des-englischen-mobiliarkreditsicherungsrechts-9783161514180? no_cache=1

order@mohrsiebeck.com

Telefon: +49 (0)7071-923-17

Telefax: +49 (0)7071-51104 